\title{
"I'm a Little More Trusting": Components of Trustworthiness in the Decision to Participate in Genomics Research for African Americans
}

\author{
Susan Racine Passmore ${ }^{\mathrm{a}}$ Amelia M. Jamison ${ }^{\mathrm{b}}$ Gregory R. Hancock ${ }^{\mathrm{c}}$ \\ Moaz Abdelwadoud $^{d}$ C. Daniel Mullins ${ }^{d}$ Taylor B. Rogers ${ }^{e}$ \\ Stephen B. Thomas ${ }^{f}$ \\ ${ }^{a}$ Collaborative Center for Health Equity, University of Wisconsin, Madison, WI, USA; ${ }^{b}$ Center for Health Equity, \\ University of Maryland, College Park, MD, USA; ${ }^{C}$ Department of Human Development and Quantitative \\ Methodology, University of Maryland, College Park, MD, USA; ${ }^{d}$ Department of Pharmaceutical Health Services \\ Research, University of Maryland, Baltimore, MD, USA; ${ }^{e}$ Department of Health Policy and Management, University of \\ California, Los Angeles, CA, USA; ${ }^{f}$ Department of Health Policy and Management, University of Maryland, \\ College Park, MD, USA
}

\section{Keywords}

African American · Research participation · Biospecimens · Genomics

\begin{abstract}
Aims: This study sought to explore the decision to participate in genomics research for African American individuals. Our overall goal was to explore (1) the attributes that significantly contribute to willingness to participate in genomics research; (2) how these attributes are interpreted (what is their meaning?); (3) how trustworthiness is estimated in the decision to participate in research (i.e., what are the symbolic representations or heuristics of trustworthiness in decision-making?); and (4) how participants see factors to counterweigh each other. Methods: We sought a methodology that would afford exploration of the compensatory nature of decision-making where some choice attributes may be
\end{abstract}

weighed differently than others as well as the use of heuristics (shortcuts to estimate key concepts in the mentally taxing task of decision-making) for concepts such as trustworthiness. We used a qualitative story deck to create hypothetical research scenarios with variable attributes (i.e., researcher race/ethnicity; institutional affiliation; research goal; and biospecimen requested) to determine how individuals find and interpret information to make decisions about research participation. These semi-structured interviews ( $n=82$ ) were conducted in African American barbershops in Baltimore City and Prince George's County, Maryland. Results: Quantitative and qualitative analysis was completed. Findings include that, even in the absence of interpersonal connection, trustworthiness can be communicated through multiple factors, such as (1) shared values with researchers and (2) familiarity. Conversely, (1) ambiguity, especially regarding the use of biospecimens, (2) negative reputations, and (3) perceptions of "hidden agendas"

\section{KARGER}

(c) 2020 S. Karger AG, Basel

E-Mail karger@karger.com

www.karger.com/phg
Susan Racine Passmore, PhD

Collaborative Center for Health Equity

School of Medicine and Public Health, University of Wisconsin

750 Highland Avenue, Madison, WI 53705 (USA)

E-Mail passmore2@wisc.edu 
were associated with a lower willingness to participate. However, the alignment of participant and research goals was weighed more heavily in decisions than other factors. Conclusion: This study finds that negatively assessed characteristics in research design do not result in automatic rejections of participation. Negative assessments can be mitigated by emphasizing the multiple factors that communicate trustworthiness in the consent process, which may improve rates of research participation.

(c) 2020 S. Karger AG, Basel

\section{Introduction}

Despite the $>2$ decades that have passed since the National Institutes of Health (NIH) Revitalization Act outlined the urgent need for the involvement of women and minorities in research, there continues to be a lack of diversity in both domestic and international health research $[1,2]$. Participant diversity has specific importance in genomics research as it is the key to understanding genetic variation in health $[3,4]$. Unfortunately, not only do barriers to the engagement of underrepresented groups, especially African Americans, persist, there is evidence for specific distrust around the collection of biospecimens and the use of biobanking [5-8]. As these research procedures are imperative to genomics research, there is an equivalent imperative to explore ways to create research protocols that are acceptable to typically underrepresented groups. Our approach in this task was to employ a unique data collection method, the qualitative story deck, to explore perceptions relative to research participation using hypothetical research scenarios with variable attributes among African American individuals in Baltimore City, Maryland, and Prince George's County, Maryland.

Our approach in this project was informed by previous research on the decision to participate in genomics research coupled with a design borrowed from the science of decision-making [9]. Overall, we were interested in how African American individuals use bits of information, like what might be afforded through recruitment materials or a recruitment encounter, to reach decisions about research participation. From decision science, our design incorporated explorations of (1) the compensatory nature of decision-making (the weighing of multiple factors which interact and may offset each other) and (2) how participants use heuristics or clues to estimate key concepts in the decision to participate in genomics research [9]. So, while previous research on willingness to participate has determined barriers (e.g., lack of trust in researchers, invasiveness for biospecimen data collection, suspicions about biobanking) and facilitators (e.g., racial concordance of research team and participant, altruism, interpersonal trust) $[6,7,10-14]$, we were interested in an exploration of the importance or value of these barriers and facilitators relative to each other and how they might interact in the decision-making process.

We set out with a specific interest in understanding how people use concepts like social trustworthiness in the decision-making process. While much of the discussion about distrust of research and researchers has focused on social (race/ethnicity, class, etc.) rather than personal factors, proposed solutions have focused on interpersonal trust built through repeated, long-term, personal interaction such as that created through community-based, participatory approaches. This study sought potential solutions along social trust, such as those built on concepts like reputation that can exist without personal interaction $[15,16]$. The difference between interpersonal trust and social trust can be illustrated in the factors influencing the decision to select a person with whom to share a secret and the decision to select an institution with which to start a savings account, respectively.

Our overall goal was to explore (1) what the attributes are that significantly contribute to willingness to participate in genomics research for African American individuals; (2) how those attributes are interpreted (what is their meaning?); (3) how trustworthiness is estimated in the decision to participate in research (i.e., what are the symbolic representations or heuristics of trustworthiness in decision-making?); and (4) how factors are weighed differentially in the process of decision-making.

\section{Methods}

\section{Procedure}

This project represents a collaboration between 2 research teams at the School of Pharmacy, University of Maryland, Baltimore, $\mathrm{MD}$, and the Maryland Center for Health Equity based in the School of Public Health at the University of Maryland, College Park, MD. Each team conducted qualitative research in local African American barbershops in their respective area. We chose to conduct research in barbershops as these settings have been described as a space for frank, even controversial discussion of many topics [17] and have increasingly been sites for health discussion and promotion [18]. Both teams had previously conducted research in black barbershops, and our familiarity with the shops contributed to participant/interviewer comfort and rapport.

Those interested in participation in the study were provided with detailed information about research goals and procedures as well as their rights as participants. They then completed a brief intake survey to gather self-reported demographic information, in-
Passmore/Jamison/Hancock/ Abdelwadoud/Mullins/Rogers/Thomas 


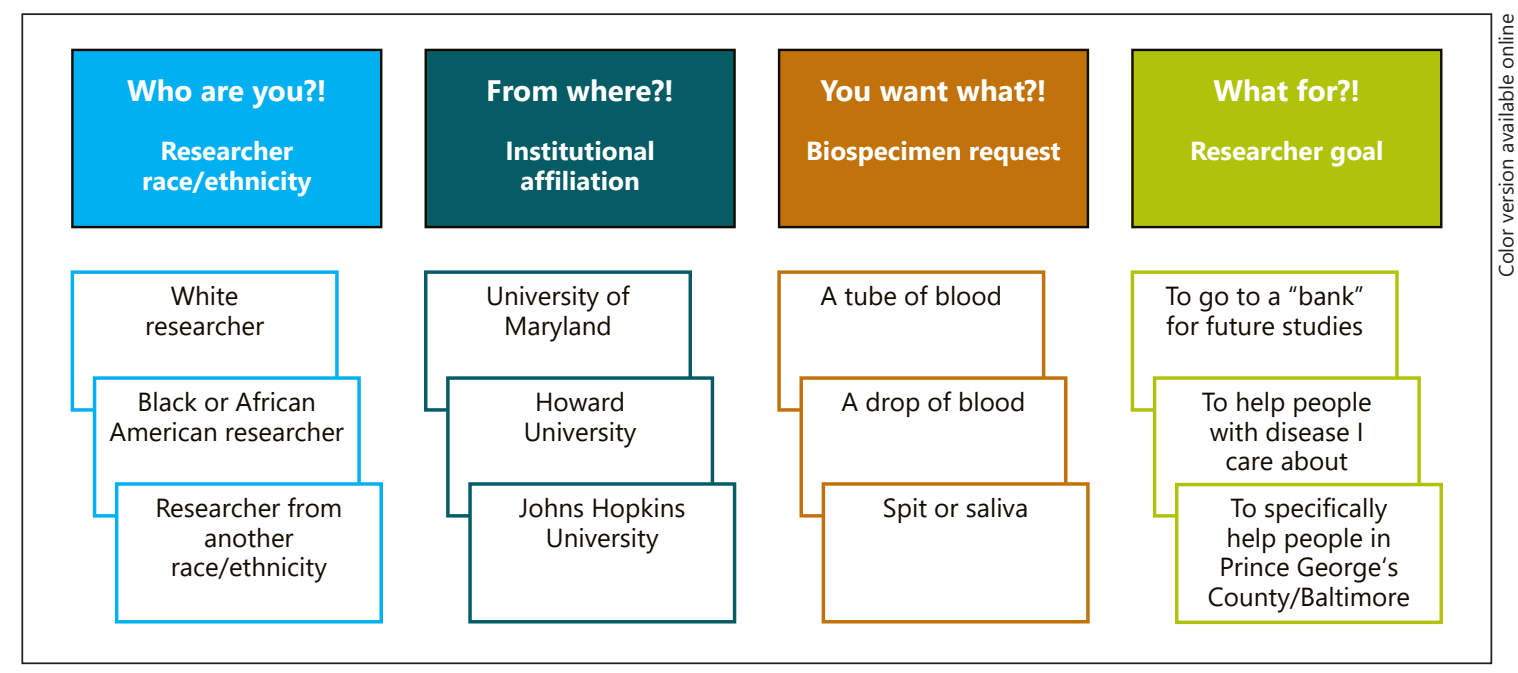

Fig. 1. Methods for this study included the use of a qualitative story deck composed of 4 sets of 3 cards representing hypothetical genomics research scenario characteristics, including researcher race/ethnicity; institutional affiliation; requested biospecimen; and research goal.

cluding race, age, education level, and household income. We then conducted semi-structured interviews built around a novel elicitation technique called a qualitative story deck (QSD). The QSD is a qualitative adaptation of a factorial survey design commonly used in decision research, sometimes called a "choice experiment," that was used to randomly create hypothetical research project scenarios including a range of alternating attributes. Participants were asked to respond to each scenario with a "decision" to participate or not. Once a decision was reached, interviewers explored participant views of each attribute and the relative contribution each made to the final decision.

Participants created research scenarios by randomly choosing cards from 4 piles representing different categories of attributes of the hypothetical research (Fig. 1). These categories were: (1) Who are you?! - race/ethnicity of the researcher; (2) From where?! - institutional affiliation of the researcher; (3) You want what?! - specific biospecimen request; and (4) What for?! - research goal. Under "Who are you?" researchers could be white, African American, or of another race/ethnicity. Institutional affiliations included local schools conducting medical or health research including an elite private university (Johns Hopkins University [JHU]), a state university (University of Maryland), and a local Historically Black College and University (HBCU; Howard University or Morgan State University). Biological sample requests included a tube of blood, a drop of blood, or spit/saliva. Finally, research goals could be "to help people with or at risk for a disease I care about"; "to specifically help people in Prince George's County or Baltimore City (local community)"; or "to go to a 'bank' for future studies." By randomly drawing a card from each pile, participants created 3 hypothetical research projects in which they could choose to participate or not. Each card could only be selected once. For each hypothetical research scenario, participants were asked to explain their answers relative to each card chosen.

Once participants responded to the 3 randomly chosen research scenarios, they were asked to use the cards to create their idea of an "ideal" project in which they would be most likely to participate and explain their reasoning. At the conclusion of this discussion, the interviewer replaced the "From where?!" card chosen by the participant in the ideal scenario with a wild card representing "the government" as an institutional affiliation. Participants were then asked about how this change impacted their decision to participate in the final hypothetical scenario.

Interviews averaged 20-30 min. Participants received a gift card incentive of USD 30 for their participation. All data were digitally recorded and transcribed. All procedures were approved by the Institutional Review Boards of the Universities of Maryland in Baltimore and College Park (\#1143589).

\section{Analysis}

Quantitative

To determine the most relevant factor to the decision to participate in research overall, respondents' multiple scenario responses were treated as separate cases, and classification and regression tree (CART) analysis $[19,20]$ was applied to all data using the SPSS 25 software (IBM, Chicago, IL, USA). CART recursively partitions the entire sample (parent node) into smaller subgroups (child nodes) based on the binary outcome variable. At each partition, this method identifies the factor that best separates data into subgroups related to the outcome, repeating the process until the sample is divided into homogenous groups and resulting in a classification tree. The benefit of this strategy, relative to other analytical techniques, is that it automatically yields combinations of factors that statistically significantly separate the data based on the outcome variable, in this case, willingness to participate in the research.

\section{Qualitative}

We used NVivo 12 software to facilitate qualitative data management and analysis. The primary goal of our analysis was to reveal "on the ground" experiences and knowledge of participants that contributed to the decision to participate in research. Coding was guided by an iterative, adapted grounded theory approach [21, 
Table 1. Frequency distribution of study participants by demographic characteristics

\begin{tabular}{|c|c|c|}
\hline & $\begin{array}{l}\text { Frequency } \\
(n=81)\end{array}$ & Percentage \\
\hline \multicolumn{3}{|l|}{ Gender } \\
\hline Female & 17 & 22 \\
\hline Male & 64 & 78 \\
\hline \multicolumn{3}{|l|}{ Age } \\
\hline $18-24$ years & 12 & 14.8 \\
\hline $25-44$ years & 46 & 56.7 \\
\hline $45-64$ years & 19 & 23.5 \\
\hline $65+$ years & 2 & 2.5 \\
\hline No response & 2 & 2.5 \\
\hline \multicolumn{3}{|l|}{ Health status } \\
\hline Fair & 3 & 3.7 \\
\hline Good & 43 & 53.1 \\
\hline Very good & 22 & 27.2 \\
\hline Excellent & 13 & 16.0 \\
\hline \multicolumn{3}{|l|}{ Education } \\
\hline Did not graduate high school & 7 & 8.6 \\
\hline High school graduate or equivalent & 20 & 24.7 \\
\hline Some college & 38 & 46.9 \\
\hline Bachelor's degree & 11 & 13.6 \\
\hline $\begin{array}{l}\text { Postgraduate degree } \\
\text { (Master's, MD, PhD, etc.) }\end{array}$ & 5 & 6.2 \\
\hline \multicolumn{3}{|l|}{ Income } \\
\hline$<20 \mathrm{k}$ & 20 & 24.7 \\
\hline $20-40 \mathrm{k}$ & 19 & 23.5 \\
\hline $40-60 \mathrm{k}$ & 16 & 19.7 \\
\hline $60-80 \mathrm{k}$ & 8 & 9.9 \\
\hline $80-100 \mathrm{k}$ & 16 & 19.7 \\
\hline No response & 2 & 2.5 \\
\hline \multicolumn{3}{|l|}{ Ethnic identitity } \\
\hline Hispanic & 6 & 7.4 \\
\hline Non-hispanic & 75 & 92.6 \\
\hline \multicolumn{3}{|l|}{ Racial identity (check all that apply) } \\
\hline Black/African American & 76 & 93.8 \\
\hline American Indian/Alaska native & 1 & 1.2 \\
\hline Other (includes multiracial) & 5 & 6.2 \\
\hline
\end{tabular}

22]. The stages of the coding process included initial open coding followed by axial coding to express connections between themes and concepts. Emergent themes were discussed with the research team for interpretation.

\section{Results}

\section{Sample}

We interviewed 82 participants, 41 in Prince George's County (College Park team) and 41 in Baltimore City (Baltimore team). Participants were predominantly male (78\%), African American (92.7\%), and non-Hispanic $(92.6 \%)$, with $78.3 \%$ between the ages of 25 and 64 years.
Overall, participants reported good to excellent health (96.3\%). Roughly two-thirds (66.7\%) reported at least some college and another $24.7 \%$ finished High School or equivalency. In terms of income, participants were more or less evenly spread among the ranges (Table 1).

\section{Quantitative Findings}

Because each participant responded to multiple research scenarios (although not every participant responded to all 5), there was a total of 404 scenarios each associated with a decision to participate or not. Of these, 80 were "ideal" scenarios chosen by participants; 80 were scenarios in which the ideal institution was replaced with the "government" institution card; and 244 were randomly selected scenarios. Of the randomly selected scenarios, a slight majority (130, or 53.3\%) resulted in a decision of willingness to participate while the rest $(114$, or 46.7\%) were rejected.

Figure 2 presents the percentage of "yes" responses resulting from the scenarios in which each characteristic (alternate forms of "attributes") appeared. The differences between characteristics were more marked in some attribute categories than others. Scenarios in which the research goal was to address a disease or condition with which the participant had a personal connection were considerably more popular $(76.3 \%$ of scenarios with "care" as characteristic were found acceptable) than those in which a biobank was proposed (only $28.9 \%$ of scenarios with "bank" as characteristic were found acceptable). There was less marked variability in the categories of biospecimen and ethnicity/race of the researcher. There was little variability in the attribute category of institution without the addition of the government "wild card." Only $22.8 \%$ of scenarios in which government appeared as the institution were found to be acceptable, making it the least popular characteristic in research scenarios, despite its placement in otherwise "ideal" scenarios chosen by participants.

As determined by CART analysis (Fig. 3) using CHAID (with minimum parent size of 10 , minimum child size of 5 , and Bonferroni probability adjustments), the most relevant factor partitioning the parent node (which started with $53.3 \%$ yes overall) was the goal of the research, yielding 3 statistically significantly different child nodes: goal of the research as benefitting the geographically community (Prince George's County or Baltimore City or $p g$ ) with percentages comparable to the parent node (56.1\% yes), goal of the research as "to help people with a disease I care about" (care) with a greatly increased willingness to participate $(75.9 \%$ yes $)$, and bank with a greatly decreased 


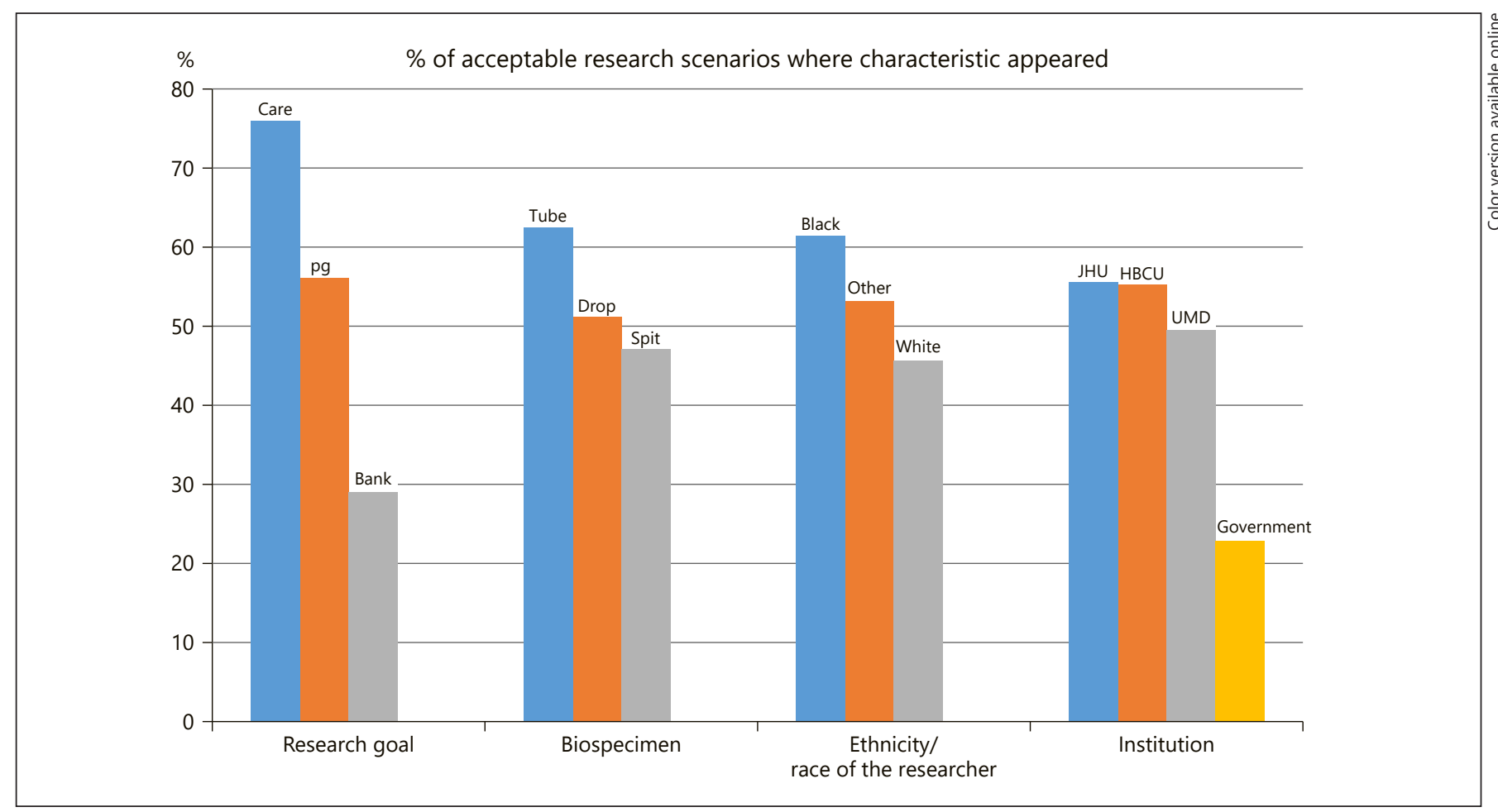

Fig. 2. Descriptive analysis determined the relative percentage of willingness to participate in a given research

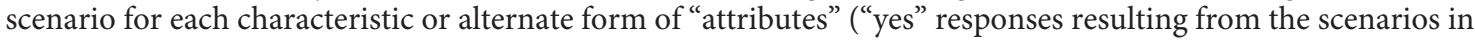
which each characteristic appeared). Of all characteristics, a research goal in line with participant values resulted in the highest percentage of willingness to participate. Use of a biobank and government-sponsored research were among the least favorable characteristics. pg, Prince George's County or Baltimore City; JHU, Johns Hopkins University; HBCU, Historically Black College and University; UMD, University of Maryland.

willingness to participate $(28.9 \%$ yes). Researcher race split the bank nodes further, and split fairly dramatically based on race, increasing willingness to participate somewhat (from 28.9 to $45.2 \%$ yes) if the researcher is black, while minimizing willingness if the researcher is not black (down to $19.2 \%$ yes). In sum, willingness to participate was maximized in this sample if the goal is care. Meanwhile, willingness to participate was minimized when the goal is bank and the researcher race is not black (i.e., white, other). This is another finding that was illustrated qualitatively. The overall correct classification rate, obtained by aggregating across all terminal nodes, is $67.6 \%$.

\section{Qualitative Findings}

Qualitatively, we found themes associated with both positive and negative assessments of research opportunities. Positive themes included: familiarity/reputation (associated with JHU and HBCU as institution; tube of blood as biospecimen) and shared goals (associated with aligned research goal; African American researcher; and HBCU as institution). Negative themes were closely related and may be viewed as somewhat reflecting the "flip side" of positive themes. These included lack of familiarity/sense (associated with saliva and drop of blood as biospecimen) and hidden agendas (associated with use of biobanking; and government as institution).

\section{Themes Contributing to the Decision to Participate}

Familiarity and Reputation

References to personal experiences were raised by participants in support of their decision to participate in research scenarios. This was clearest in relation to the attribute categories of institution and biospecimen where participants framed their acceptance of scenarios with reference to existing knowledge or experience. Participants favored institutions they felt had a good reputation or with which they had positive experiences (Table 2). Interestingly, these assessments did not always relate to research specifically but also included experiences in healthcare encounters or as employers. Overall, all 3 uni- 


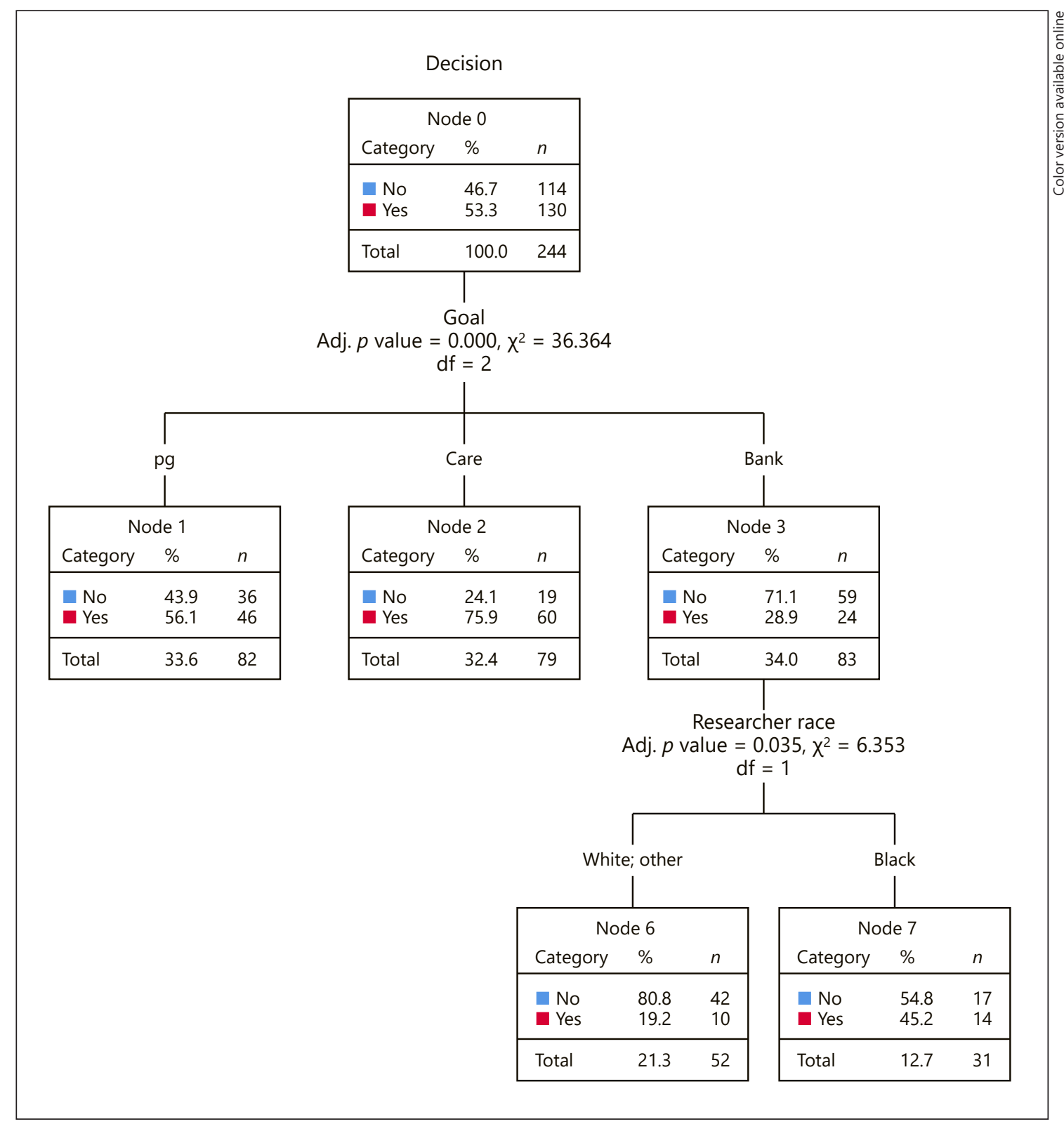

Fig. 3. Regression tree analysis determined that the most relevant factor partitioning the parent node was the goal of the research. Goal of the research such as "to help people with a disease I care about" (care) was associated with a greatly increased willingness to participate and bank (use of biobank) with a greatly decreased willingness to participate. Researcher race split the bank nodes further increasing willingness to participate somewhat if the researcher is black, while minimizing willingness if the researcher is not black.

versities were seen as comparable, with Howard University and JHU recognized as more well known. Regarding biospecimen collection, participants preferred techniques with which they were familiar. Frequently, this took the form of an association between providing a tube of blood for research and for a blood bank.

\section{Shared Goals}

Table 3 presents the theme of shared goals with related subthemes and categories. This theme consists of participant interpretations of scenario characteristics as evidence of alignment with personal goals. This connection is relatively obvious when the research goal was "to help people with or at risk for a disease I care about” (care). 
Table 2. Familiarity and reputation theme, subthemes, and selected participant quotations

\begin{tabular}{|c|c|c|c|}
\hline Theme & Characteristic & & Selected quotes \\
\hline $\begin{array}{l}\text { Familiarity } \\
\text { and } \\
\text { reputation }\end{array}$ & Institutions & $\begin{array}{l}\text { Reputation } \\
\text { as university }\end{array}$ & $\begin{array}{l}\text { So, my sister went to University of Maryland, she graduated there. I know a lot of } \\
\text { people from University of Maryland. So, I think just the environment, I'm a little } \\
\text { more trusting. }\end{array}$ \\
\hline
\end{tabular}
... John Hopkins is actually the best nursing school, the number one nursing school right now. So, I would go with that, because I am in the field of nursing. Yeah, I would go with this.
I chose Howard University because Howard University is a very reputable school. They have a great medical program. And I know a few people who have graduated from Howard, from their medical program, who are flourishing right now.

\begin{tabular}{|c|c|c|}
\hline & \multirow[t]{3}{*}{$\begin{array}{l}\text { Reputation } \\
\text { as healthcare } \\
\text { setting or other }\end{array}$} & $\begin{array}{l}\text { My father was diagnosed } 3 \text { years ago with glioblastoma which was a brain tumor. } \\
\text { Unfortunately, it was stage } 4 \text {, so he went through some extensive surgery and } \\
\text { chemotherapy as well as radiation. And he passed } 2 \text { years ago. ... So, I think in this } \\
\text { situation, because it's more of an intimate, because I see Johns Hopkins, I think I } \\
\text { would be okay with it. }\end{array}$ \\
\hline & & I used to go to that hospital a lot. It's nice, yeah. \\
\hline & & $\begin{array}{l}\text { But Johns Hopkins, I really don't like Johns Hopkins. Call it a good hospital but } \\
\text { yeah ... } \\
\text { I don't like the way they treat their employees. They don't pay them. }\end{array}$ \\
\hline \multirow[t]{2}{*}{ Biospecimens } & \multirow[t]{2}{*}{ Familiarity } & $\begin{array}{l}\text { I guess this one is pretty straightforward. Donating blood, helping others, I think } \\
\text { that is pretty self-explanatory. I've donated blood in the past, so this area I would be } \\
\text { familiar with. }\end{array}$ \\
\hline & & $\begin{array}{l}\text { I chose a tube of blood again because I'm just into helping people. I give blood all } \\
\text { the time. So one tube, I give a bag of blood. So one tube wouldn't hurt anybody. } \\
\text { And if I can save a life. }\end{array}$ \\
\hline
\end{tabular}

The shared goals theme also ran through evaluations of the race of the researcher and institution. In these cases, participants saw alignment relating to the support of the African American community or African American individuals. In these cases, participants' willingness to participate rested on, among other things, a desire to "be a big supporter of black people" or provide "opportunity" (Table 3).

\section{Themes Associated with Refusal to Participate \\ Lack of Familiarity and Sense}

These themes were associated with negative assessments. For example, saliva collection was seen by some as "just weird," "awkward," and "nasty." They were also frequently associated with suspicion (Table 4). However, these suspicions did not rise to the level of "hidden agendas."

\section{Hidden Agendas}

The theme of "hidden agendas" covers the majority of motivations for the decision not to participate in research. The characteristics discussed in these terms were associ- ated with more than "weirdness." They were associated with suspicion and a fear of harmful intent based on reputation (JHU, white researcher), ambiguity (biobanking), or perceptions of outright opposition (government). The theme of hidden agendas was found in discussions of the 2 least popular characteristics - biobanking as research goal and government as institution - where participants also brought up specific fears about cloning and other feared abuses of science. Table 5 presents this theme with selected participant quotations.

\section{Discussion}

Our findings affirm the complexity of the decision to participate in research and have implications for both genomics research and health research more broadly defined. Overall, we find support for previous observations of altruism as a strong motivator for research participation among African Americans [13, 23]. Findings also confirm the importance of trust in the decision to par- 
Table 3. Shared goals theme, subthemes, and selected participant quotations

\begin{tabular}{|c|c|c|c|}
\hline Theme & Category & Subtheme & Selected quotes \\
\hline \multirow[t]{6}{*}{$\begin{array}{l}\text { Shared } \\
\text { goals }\end{array}$} & \multirow[t]{2}{*}{$\begin{array}{l}\text { Goal of the } \\
\text { research }\end{array}$} & \multirow[t]{2}{*}{$\begin{array}{l}\text { Personal } \\
\text { connection with } \\
\text { research goal }\end{array}$} & $\begin{array}{l}\text { So I'll be - I mean because now it's more personal. ... Once that you indicate that it's a } \\
\text { disease that I care about, it's now more personal for me. And I'll be more inclined to give a } \\
\text { tube or } 2 \text { or } 3 \text { or } 4 \text {, doesn't matter, because now I know that this is a disease that I'm aware } \\
\text { of, I care about, and I'm willing to help with. }\end{array}$ \\
\hline & & & $\begin{array}{l}\text { No, I'm a big believer in medical research, so and the good things that it brings about, } \\
\text { because I have a handicapped son, born handicapped with birth defects, so I am a big, } \\
\text { I'm into research. }\end{array}$ \\
\hline & \multirow[t]{2}{*}{$\begin{array}{l}\text { Race of the } \\
\text { researcher }\end{array}$} & \multirow[t]{2}{*}{$\begin{array}{l}\text { Support of the } \\
\text { black community }\end{array}$} & $\begin{array}{l}\text { And so it'll help my race, why not? It's just domino effect when it comes to black people. } \\
\text { Because I'm a big supporter of black people, black business. The reason, I like the reason, } \\
\text { to help people, and it's even better, a Black or African American researchers, black food, } \\
\text { black carry-outs, I do it all. }\end{array}$ \\
\hline & & & $\begin{array}{l}\text { I picked a black or African American researcher because I am black myself. And I'm all } \\
\text { for black empowerment, seeing my people rise to the top and do something for the better } \\
\text { of the community, and for themselves. }\end{array}$ \\
\hline & \multirow[t]{2}{*}{ Institution } & \multirow[t]{2}{*}{$\begin{array}{l}\text { Support of the } \\
\text { black community }\end{array}$} & $\begin{array}{l}\text { A lot of times, if all things are equal, I would like to give a person of my color the } \\
\text { opportunity. So Howard University, African American researcher. But at the end of the } \\
\text { day, this is more important to me than "the who," "the how," "where's it going," "what's } \\
\text { the cause for"? }\end{array}$ \\
\hline & & & $\begin{array}{l}\text { HBCU, I think we had the same mantra, we had the same reason why we're doing what } \\
\text { we're doing to help people out. I'm not saying anything against white people, because I } \\
\text { know Caucasians and other races that you definitely want to help everybody. But that } \\
\text { would just be my comfort level. }\end{array}$ \\
\hline
\end{tabular}

Table 4. Lack of familiarity theme, subthemes, and selected participant quotations

\begin{tabular}{|c|c|c|c|}
\hline Theme & Category & Subtheme & Selected quotes \\
\hline \multirow[t]{2}{*}{$\begin{array}{l}\text { Lack of } \\
\text { familiarity }\end{array}$} & \multirow[t]{2}{*}{$\begin{array}{l}\text { Biospecimen: spit, } \\
\text { drop of blood }\end{array}$} & \multirow[t]{2}{*}{$\begin{array}{l}\text { Lack of familiarity/ } \\
\text { making sense }\end{array}$} & $\begin{array}{l}\text { Why wouldn't she use a tube or half? Why would she use a drop? } \\
\text { That's suspicious to me... That creates suspicion. A drop? No, } \\
\text { thank you. It doesn't make sense. }\end{array}$ \\
\hline & & & $\begin{array}{l}\text {... but what are you going to do - how does my spit help them? } \\
\text { What the hell are you going to do with it? Like just vagueness is } \\
\text { what gets me. }\end{array}$ \\
\hline
\end{tabular}

ticipate [24-26]. They also go on to identify the factors that contribute to estimations of trustworthiness, which can be understood with reference to conceptions of social trust as previously described [16, 27]. Qualitative themes appear to align with the components of social or institutional trust described as trust in motive and trust in competence, which have been shown to influence risk perception and decision-making [15, 16, 28, 29]. As Figure 4 illustrates, trustworthiness regarding motive was expressed both positively (shared goals) and negatively (hidden agendas and bad reputation). Trustworthiness regarding competence was also expressed positively (familiarity and good reputation) and negatively (lack of familiarity).
At the level of research scenario characteristics, trustworthiness in motive was signified as the presence of a research goal aligned with one's personal values; an African American researcher; and an affiliation with an HBCU. It is important to note that these characteristics were interpreted to be aligned with personal goals of health research and support of the African American community, indicating that participants are influenced by the ability of research activities to advance careers in the African American community, a finding supported by previous research [30]. Trustworthiness in competence was signified by the presence of a positive institutional reputation as a distinguished research university and caring healthcare facility. In both cases, we note that estima- 
Table 5. Hidden agendas theme, subthemes, and selected participant quotations

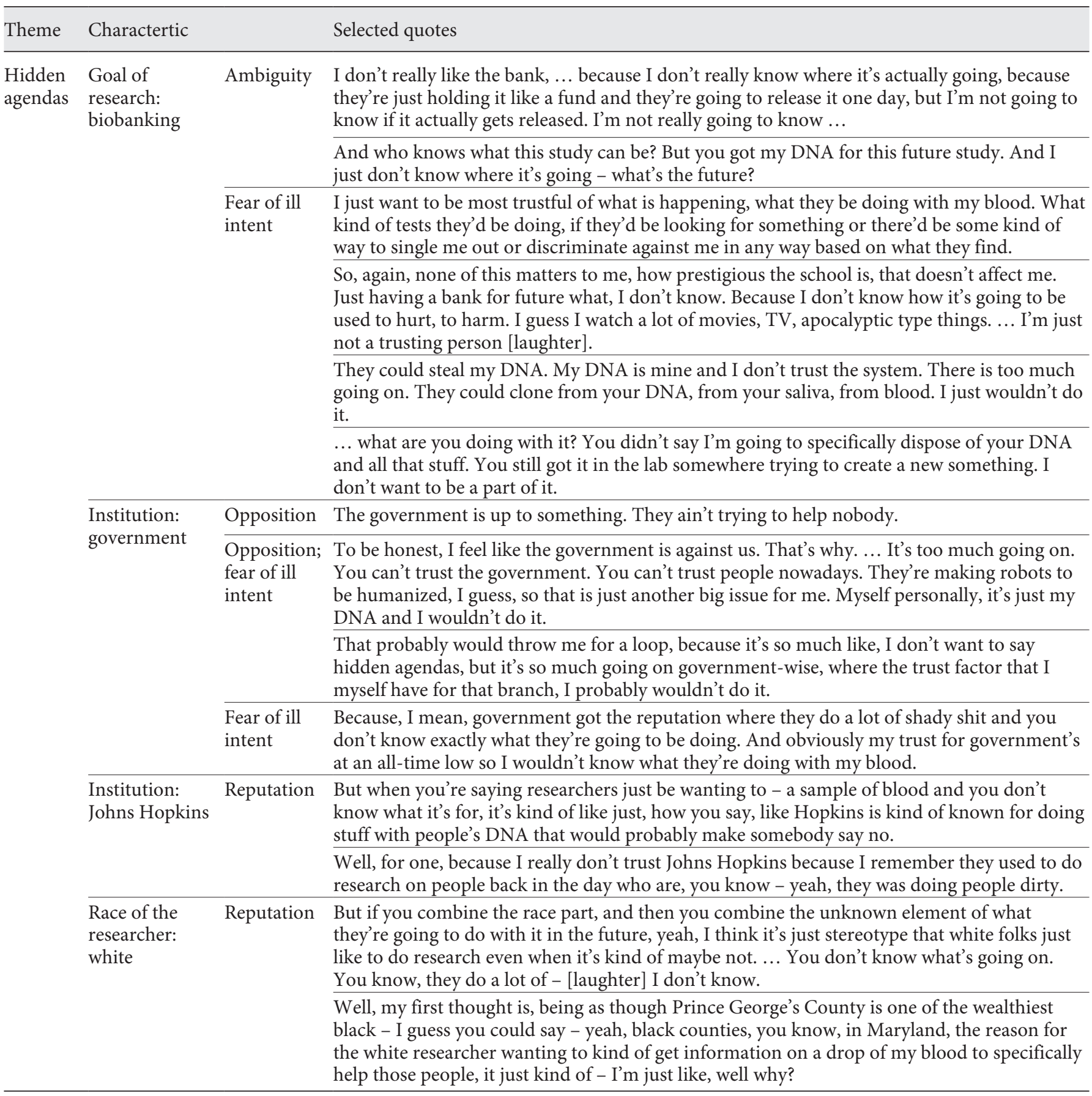

tions of trustworthiness extend beyond the borders of a single research opportunity [31].

Through quantitative analysis, we determined that some factors influenced decisions to participate in research more than others. The goal of the research was most important, influencing both positive (aligned with personal goals) and negative decisions (use of biobank). Overall, we found evidence that characteristics associated with trust in motive, either positively (aligned research goal; African American researcher; and HBCU as institution) or negatively (use of biobanking; and government as institution) are most influential in the decision to participate in research. This finding 


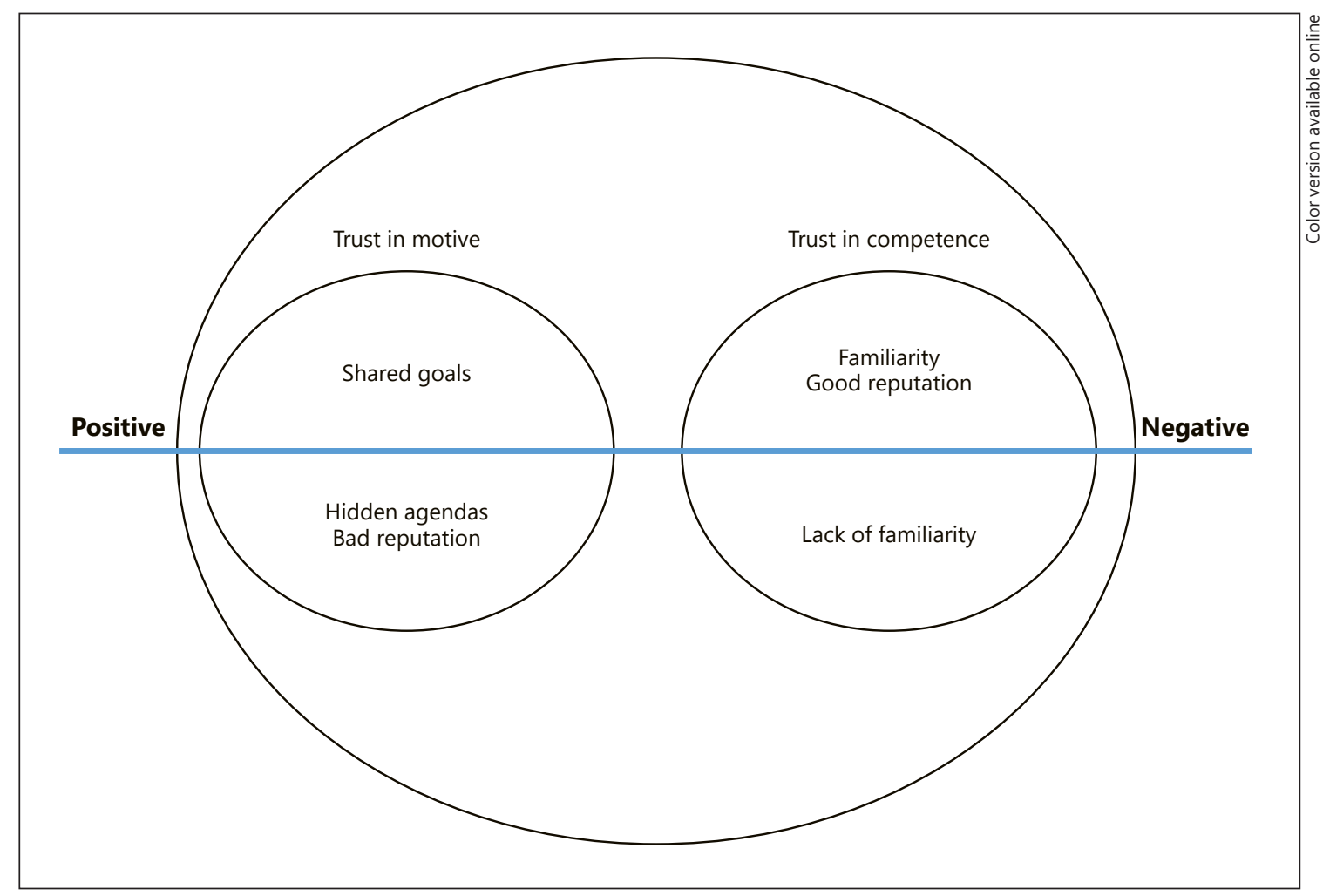

Fig. 4. Conceptual model of study findings emphasizing the alignment of qualitative themes (in both positive and negative expressions) with the concepts of "trust in motive" and "trust in competence," 2 aspects of social trust.

adds weight to the negative assessments of biobanking and broad consent reported by other researchers $[6,7,32]$ and assertions of goal alignment as fundamental to trust in the research enterprise [33, 34]. In addition, our findings indicate that there are factors that can make "untrustworthy" factors more acceptable. In this case, race of the researcher minimized participant fears regarding biobanking. Potentially, other characteristics expressing "shared goals" may have similar effects.

\section{Conclusions}

Initially, we found that trust can be determined by participants even in the absence of interpersonal connections and that prospective participants estimate trustworthiness through several heuristics. Chief among these is goal alignment such as that expressed by research studies that reflect the needs and interests of the African American community in terms of both health and diversity/inclusion goals. Participants are interested in the potential of research activities to advance the careers of other African
Americans and see this as an indication of researchers as "on their side." The importance of shared goals/goal alignment may be greatest in the case of research perceived as "high risk" for research abuse [8]. As such, researchers should consider seeking community input to set research goals and guide recruitment approaches. This may be accomplished through the use of community advisory boards [35].

Another way to express affinity with underserved populations would be to ensure that research activities promote diversity and equity (i.e., explicitly seeking diversity in research teams particularly at leadership levels). The return of medically actionable findings to participants and healthcare providers may also produce similar results $[35,36]$.

Researchers should also be aware of the salience of institutional reputation and performance on the decision to participate and that participant assessment of institutional reputation/performance is based on a broad definition of the institution to perceptions of research, healthcare provision, and past research abuse. Researchers and research team members should be aware of their institu- 
tional reputation and history. Although individuals may have little control over institutional policies, there have been suggestions that awareness and acknowledgement may serve to allay participant concerns $[37,38]$.

Factors that detract from trustworthiness include negative reputations but, even more importantly, ambiguity and the fear of the "hidden agendas" of researchers and institutions perceived to be threats to the community. We find that vague or unfamiliar protocols or procedures can be interpreted as reasons for suspicion, especially when ambiguity extends to how biospecimens will be used. Researchers would do well to ensure that research protocols "make sense" to potential participants. This too suggests the value of community input. Like others [32,39-42], we also found strong evidence to support the use of active consent approaches rather than broad consent. In this we add to an existing but growing body of literature that suggests alternatives such as dynamic or tiered consent for research with marginalized communities [32, 39, 40]. Overall, researchers should note that the existence of negatively assessed characteristics in research design does not result in automatic rejections of participation but that these effects may be lessened through the incorporation of those factors that have the potential to communicate trustworthiness.

\section{Limitations}

This study has several important limitations. Initially, this study was designed as a qualitative inquiry and, therefore, the quantitative data presented here was not collected as it would have been if our intentions were for a quantitative project. In the future, we hope to explore factor analytic approaches to the question of willingness to participate in research. Such a direction may afford a larger sample size and, thus, greater representativeness of findings. In addition, our participants provided insight only on the factors that we decided to include based on a review of the literature and feasibility concerns (i.e., number of variables that could be included in research scenarios). It would be interesting to include a variable regarding financial incentives, for example. Relatedly, due to the exploratory nature of this study and restrictions of format, we chose not to fully define some concepts. For example, the concept of "government" was left to participants to define. Further research might explore more specific entities such as the NIH or Centers for Disease Control and Prevention. Finally, it is important to note that while participants provided a rich understanding of their hypothetical decision to participate in research, our findings would be stronger had we been able to observe the actual decision to participate or not in reaction to genuine recruitment efforts.

\section{Acknowledgements}

We would like to thank the participants who willingly gave their valued time to participate in this work.

\section{Statement of Ethics}

All procedures were approved by the Institutional Review Boards of the Universities of Maryland in Baltimore and College Park (\#1143589).

\section{Disclosure Statement}

The authors have no conflicts of interest to declare.

\section{Funding Sources}

This research was funded by a seed grant from the University of Maryland, College Park and University of Maryland, Baltimore. Further support for this project came from a University of Maryland, College Park, and University of Maryland, Baltimore, Collaborative Seed Grant. This project also received support from the Clinical and Translational Science Award (CTSA) program, through the NIH National Center for Advancing Translational Sciences (NCATS), grant UL1TR002373. The content is solely the responsibility of the authors and does not necessarily represent the official views of funders.

\section{Author Contributions}

All authors made substantial contributions to the work and approved the final version to be published. They all agreed to be accountable for all aspects of the work in ensuring that questions related to the accuracy or integrity of any part of the work are appropriately investigated and resolved. Drs. Susan Racine Passmore, Stephen B. Thomas, and C. Daniel Mullins were responsible for the concept of the work and research design. Dr. Moaz Abdelwadoud and Ms. Taylor B. Rogers contributed through data collection and revising the manuscript critically for important intellectual content. Susan Racine Passmore, Amelia M. Jamison, and Gregory R. Hancock were responsible for initial analysis and draft preparation as well as subsequent revisions. Drs. Stephen B. Thomas and C. Daniel Mullins also participated in revising the manuscript critically for important intellectual content.

\section{References}

Public Health Genomics 2019;22:215-226

Knepper TC, McLeod HL. When will clinical trials finally reflect diversity? Nature. 2018 May;557(7704):157-9.

2 Duma N, Vera Aguilera J, Paludo J, Haddox CL, Gonzalez Velez M, Wang Y, et al. Representation of Minorities and Women in Oncology Clinical Trials: Review of the Past 14 Years. J Oncol Pract. 2018 Jan;14(1):e1-10. 
3 Hindorff LA, Bonham VL, Brody LC, Ginoza ME, Hutter CM, Manolio TA, et al. Prioritizing diversity in human genomics research. Nat Rev Genet. 2018 Mar;19(3):175-85.

4 Sirugo G, Williams SM, Tishkoff SA. The Missing Diversity in Human Genetic Studies. Cell. 2019 Mar;177(1):26-31.

5 Haldeman KM, Cadigan RJ, Davis A, Goldenberg A, Henderson GE, Lassiter D, et al. Community engagement in US biobanking: multiplicity of meaning and method. Public Health Genomics. 2014;17(2):84-94.

6 Lemke AA, Wolf WA, Hebert-Beirne J, Smith ME. Public and biobank participant attitudes toward genetic research participation and data sharing. Public Health Genomics. 2010; 13(6):368-77.

7 Cohn EG, Husamudeen M, Larson EL, Williams JK. Increasing participation in genomic research and biobanking through community-based capacity building. J Genet Couns. 2015 Jun;24(3):491-502.

8 Lee SS, Cho MK, Kraft SA, Varsava N, Gillespie K, Ormond KE, et al. "I don't want to be Henrietta Lacks": diverse patient perspectives on donating biospecimens for precision medicine research. Genet Med. 2019 Jan; 21(1):107-13.

9 Bruch E, Feinberg F. Decision-Making Processes in Social Contexts. Annu Rev Sociol. 2017 Jul;43(1):207-27.

10 George S, Duran N, Norris K. A systematic review of barriers and facilitators to minority research participation among African Americans, Latinos, Asian Americans, and Pacific Islanders. Am J Public Health. 2014 Feb; 104(2):e16-31.

11 Haley SJ, Southwick LE, Parikh NS, Rivera J, Farrar-Edwards D, Boden-Albala B. Barriers and Strategies for Recruitment of Racial and Ethnic Minorities: Perspectives from Neurological Clinical Research Coordinators. J Racial Ethn Health Disparities. 2017 Dec;4(6) 1225-36.

12 Hughes TB, Varma VR, Pettigrew C, Albert MS. African Americans and clinical research: evidence concerning barriers and facilitators to participation and recruitment recommendations. Gerontologist. 2017 Apr;57(2):34858.

13 Yancey AK, Ortega AN, Kumanyika SK. Effective recruitment and retention of minority research participants. Annu Rev Public Health. 2006;27(1):1-28.

14 Halbert CH, McDonald J, Vadaparampil S, Rice L, Jefferson M. Conducting Precision Medicine Research with African Americans. PLoS One. 2016 Jul;11(7):e0154850.

15 van 't Wout M, Sanfey AG. Friend or foe: the effect of implicit trustworthiness judgments in social decision-making. Cognition. 2008 Sep;108(3):796-803.
16 Twyman M, Harvey N, Harries C. Trust in motives, trust in competence: separate factors determining the effectiveness of risk communication. Judgm Decis Mak. 2008;3:111.

17 Mills QT. "I've Got Something to Say": The Public Square, Public Discourse, and the Barbershop. Radic Hist Rev. 2005;2005(93):1929.

18 Linnan L, Thomas S, D'Angelo H, Ferguson YO. African American barbershops and beauty salons. Community Organizing and Community Building for Health and Welfare; 2012.

19 Breiman L. Classification and regression trees. Routledge; 2017.

20 Lemon SC, Roy J, Clark MA, Friedmann PD, Rakowski W. Classification and regression tree analysis in public health: Methodological review and comparison with logistic regression. Ann Behav Med. 2003 Dec;26(3):17281.

21 Strauss A, Corbin JM. Grounded Theory in Practice. Sage; 1997.

22 Sbaraini A, Carter SM, Evans RW, Blinkhorn A. How to do a grounded theory study: a worked example of a study of dental practices. BMC Med Res Methodol. 2011 Sep;11(1):128.

23 Thoman DB, Brown ER, Mason AZ, Harmsen AG, Smith JL. The Role of Altruistic Values in Motivating Underrepresented Minority Students for Biomedicine. Bioscience. $2015 \mathrm{Feb}$ 65(2):183-8.

24 Corbie-Smith G, Thomas SB, St George DM. Distrust, race, and research. Arch Intern Med. 2002 Nov; 162(21):2458-63.

25 Ford AF, Reddick K, Browne MC, Robins A, Thomas SB, Crouse Quinn S. Beyond the cathedral: building trust to engage the African American community in health promotion and disease prevention. Health Promot Pract. 2009 Oct; 10(4):485-9.

26 Wilkins $\mathrm{CH}$. Effective Engagement Requires Trust and Being Trustworthy. Med Care. 2018 Oct;56 Suppl 10 Suppl 1:S6-8.

27 Portes A. Social Capital: Its Origins and Applications in Modern Sociology. Annu Rev Sociol. 1998;24(1):1-24.

28 Jamison AM, Quinn SC, Freimuth VS. "You don't trust a government vaccine": narratives of institutional trust and influenza vaccination among African American and white adults. Soc Sci Med. 2019 Jan;221:87-94.

29 Wiltshire J, Allison JJ, Brown R, Elder K. African American women perceptions of physician trustworthiness: A factorial survey analysis of physician race, gender and age. AIMS Public Health. 2018 May;5(2):122-34.

30 Fryer CS, Passmore SR, Maietta RC, Petruzzelli J, Casper E, Brown NA, et al. The Symbolic Value and Limitations of Racial Concordance in Minority Research Engagement. Qual Health Res. 2016 May;26(6):830-41.
31 Scharff DP, Mathews KJ, Jackson P, Hoffsuemmer J, Martin E, Edwards D. More than Tuskegee: understanding mistrust about research participation. J Health Care Poor Underserved. 2010 Aug;21(3):879-97.

32 Garrison NA, Sathe NA, Antommaria AH, Holm IA, Sanderson SC, Smith ME, et al. A systematic literature review of individuals' perspectives on broad consent and data sharing in the United States. Genet Med. 2016 Jul; 18(7):663-71.

33 Cacari-Stone L, Wallerstein N, Garcia AP, Minkler M. The promise of communitybased participatory research for health equity: a conceptual model for bridging evidence with policy. Am J Public Health. 2014 Sep; 104(9):1615-23.

34 Minkler M, Wallerstein N. CommunityBased Participatory Research for Health: From Process to Outcomes. John Wiley \& Sons; 2011.

35 Shaibi GQ, Kullo IJ, Singh DP, Sharp RR, De Filippis E, Cuellar I, et al. Developing a Process for Returning Medically Actionable Genomic Variants to Latino Patients in a Federally Qualified Health Center. Public Health Genomics. 2018;21(1-2):77-84.

36 Schwartz ML, McCormick CZ, Lazzeri AL, Lindbuchler DM, Hallquist ML, Manickam $\mathrm{K}$, et al. A Model for Genome-First Care: Returning Secondary Genomic Findings to Participants and Their Healthcare Providers in a Large Research Cohort. Am J Hum Genet. 2018 Sep;103(3):328-37.

37 Reverby SM. Invoking “Tuskegee”: problems in health disparities, genetic assumptions, and history. J Health Care Poor Underserved. 2010 Aug;21(3 Suppl):26-34.

38 Thomas SB, Quinn SC, Butler J, Fryer CS, Garza MA. Toward a fourth generation of disparities research to achieve health equity. Annu Rev Public Health. 2011;32(1):399416

39 Nembaware V, Johnston K, Diallo AA, Kotze MJ, Matimba A, Moodley K, et al. A framework for tiered informed consent for health genomic research in Africa. Nat Genet. 2019 Nov;51(11):1566-71.

40 Budin-Ljøsne I, Teare HJ, Kaye J, Beck S, Bentzen HB, Caenazzo L, et al. Dynamic Consent: a potential solution to some of the challenges of modern biomedical research. BMC Med Ethics. 2017 Jan;18(1):4.

41 Goodman D, Johnson CO, Wenzel L, Bowen $\mathrm{D}$, Condit C, Edwards KL. Consent Issues in Genetic Research: Views of Research Participants. Public Health Genomics. 2016;19(4): $220-8$.

42 Thiel DB, Platt J, Platt T, King SB, Fisher N, Shelton $\mathrm{R}$, et al. Testing an online, dynamic consent portal for large population biobank research. Public Health Genomics. 2015; 18(1):26-39. 